\title{
Health Policy Research and Foundation Grantmaking
}

\section{Identifying Areas Where Foundations Fill the Gap}

\section{March 2004 / THE FOUNDATION CENTER}

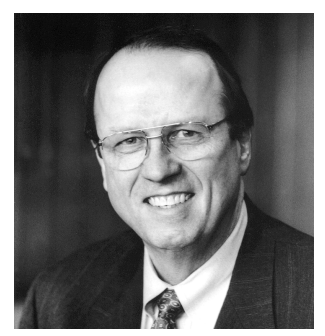

\author{
by Bradford H. Gray, Ph.D. \\ Director of the Division of Health \& Science Policy \\ at the New York Academy of Medicine and \\ Editor of The Milbank Quarterly, a multidisciplinary journal \\ of population health and health policy published by the \\ Milbank Memorial Fund
}

$\mathrm{T}$ he Foundation Center's report on health policy grantmaking in 1995 and 2002, Update on Foundation Health Policy Grantmaking, ${ }^{1}$ provides a fascinating window into the philanthropic sector's activities during a period in which health policy vastly declined as a central governmental concern. An important role of the nonprofit sector is to complement government, undertaking activities that are out of favor or overlooked by government. This report and its predecessor, ${ }^{2}$ which traced trends in health policy grantmaking between 1990 and 1995, show foundations' activities during a particularly interesting time in the health policy history of the United States.

Early in this period, the Clinton Administration made a quite comprehensive but spectacularly unsuccessful effort to address a broad range of policy issues in its health reform proposal. Its defeat was followed by many years in which deep political divisions made major new federal initiatives so implausible that they were barely discussed. It has often been observed that health policy activity shifted substantially to the state and local levels. Judging from the Foundation Center's report, it also appears to have shifted to the nation's foundations.

The report not only shows that foundation spending on health policy increased enormously since the defeat of the Clinton proposal, but also that one in eight foundation dollars spent on health in 2002 went to policy-related activities. This is a markedly different allocation of health resources than is found in the federal government and is evidence that foundations have sought to provide an impetus for change.

\section{A Comparison of Federal and Foundation Health Policy Support}

An instructive perspective on the larger importance of foundations' commitment to health policy in the years since the defeat of the Clinton proposal comes from the history of the federal government's lead health policy research agency-the Agency for Health Care Policy and Research (AHCPR). AHCPR was created legislatively in 1989, just before the Foundation Center began to track foundations' health policy activities. Between 1990 and 1995, years in which foundation giving for health policy increased from $\$ 30.9$ million to $\$ 99.8$ million, the Agency's budget grew from $\$ 98$ million to $\$ 159$ million.

AHCPR was the first executive branch health agency with the word "policy" in its name, and although much of its work did not bear directly on policy, it was 
involved in policy in several ways. Much of the research it supported was policy oriented; many of its staffers served on the working groups that developed the Clinton health reform proposal; its staff members and its data were used to generate budget estimates for the proposal; and it supported the development and publication of practice guidelines that influenced payment policies of Medicare and private insurers.

When control of Congress changed in 1995, AHCPR's budget came under severe attack, and it narrowly avoided elimination, along with dozens of other agencies that met that fate that year. ${ }^{3}$ AHCPR's policy activities (both real and imagined) had made enemies, and for a government agency that was dependent on appropriations, this was dangerous. Even the word "policy" in its name was a problem. For some critics, this identified the Agency with the hated Clinton reform proposal, rendered it unnecessary because the proposal had been defeated, and implied a positive orientation toward an expanded federal role in health care. The Agency's critics tried at several stages of the House budget process to reduce its 1996 budget to zero, but it managed to escape with a severe cut. It was not until 1999 that its budget returned to the fiscal 1995 level (passed before control of Congress changed).

The Agency and its friends saw that the word "policy" had become a liability, and when re-authorizing legislation was passed in 1999, the word disappeared and the Agency for Healthcare Research and Quality
(AHRQ) was born. AHRQ did well in budgetary terms, with a budget that approximately doubled to more than $\$ 300$ million between 1999 and 2002. Even with this increase, its budget is smaller then the combined health policy grantmaking activities of foundations in 2002 (almost \$360 million), and the Agency's center of gravity is on issues (quality of care, medical errors, and effectiveness research) that are closer to medical practice than to health policy. The Agency also fills important roles in collecting data and making them available to researchers.

Foundations deserve recognition for increasing their involvement in supporting health policy activities during a period when this became dangerous for federal agencies. In supporting work related to health policy, foundations are engaging issues that would otherwise get insufficient attention.

\section{The Relationship between Health Policy Activities of Foundations and Researchers}

Another perspective on foundations' grantmaking activities in health policy can be found in the work of researchers. Their output is represented in journal articles from medicine, public health, health services research, and related fields that are catalogued in the MedLine system (www.ncbi.nlm.nih.gov/entrez/query.fcgi) at the National Library of Medicine. These publications

Distribution of MedLine Articles on U.S. Health Policy, 1990, 1995, and 2002

\begin{tabular}{|c|c|c|c|c|c|c|}
\hline \multirow[b]{2}{*}{ U.S. Policy Topic ${ }^{1}$} & \multicolumn{2}{|c|}{1990} & \multicolumn{2}{|c|}{1995} & \multicolumn{2}{|c|}{2002} \\
\hline & No. & $\%$ & No. & $\%$ & No. & $\%$ \\
\hline \multicolumn{7}{|l|}{ Health Care Cost, Quality, and Reform } \\
\hline Medicare/Medicaid, HMOs, and Private Insurance & 306 & 21.1 & 945 & 33.6 & 536 & 25.2 \\
\hline Health Care Reform & 17 & 1.2 & 1,416 & 50.3 & 216 & 10.1 \\
\hline Health Care Financing & 375 & 25.8 & 1,239 & 44.0 & 594 & 27.9 \\
\hline Cost Containment/Managed Care & 87 & 6.0 & 533 & 18.9 & 181 & 8.5 \\
\hline Health Care Access & 154 & 10.6 & 263 & 9.3 & 181 & 8.5 \\
\hline \multicolumn{7}{|l|}{ Health Policy-Special Topics } \\
\hline Mental Health/Substance Abuse & 124 & 8.5 & 171 & 6.1 & 160 & 7.5 \\
\hline Smoking Prevention/Tobacco Addiction & 43 & 3.0 & 57 & 2.0 & 91 & 4.3 \\
\hline Reproductive Health & 82 & 5.6 & 57 & 1.0 & 19 & 0.9 \\
\hline End-of-Life Care/Right-to-Die Issues & 23 & 1.6 & 32 & 1.1 & 27 & 1.3 \\
\hline HIVIAIDS & 155 & 10.7 & 181 & 6.4 & 80 & 3.8 \\
\hline Long-term and Chronic Care & 36 & 2.5 & 43 & 1.5 & 37 & 1.7 \\
\hline Bioethics & 230 & 15.8 & 301 & 10.7 & 243 & 11.4 \\
\hline Asthma & 0 & 0.0 & 3 & 0.1 & 8 & 0.4 \\
\hline Environmental Health & 13 & 0.9 & 13 & 0.5 & 29 & 1.4 \\
\hline Total $^{2}$ & 1,452 & 100.0 & 2,815 & 100.0 & 2,130 & 100.0 \\
\hline
\end{tabular}

Source: National Library of Medicine on-line MedLine system (www.ncbi.nlm.nih.gov/entrez/query.fcgi).

'The policy topics were slightly modified from those used in the Foundation Center report to produce more effective MedLine searches. All of the searches also included the terms Policy and United States. Articles can appear in more than one search.

${ }^{2}$ This total is based on a search for Policy and United States and is not a sum of the column. 
serve as a good indicator of the issues in which health policy researchers are engaged. They also provide a means to ask: To what extent do trends in policy publications mirror grantmaking trends?

The 1998 and 2004 Foundation Center reports show that grantmaking for health policy increased dramatically in both periods, from approximately $\$ 31$ million in 1990 to $\$ 100$ million in 1995 to $\$ 360$ million in 2002. The average annual rate of increase between 1990 and 1995 was close to 27 percent, a rate that slackened slightly to 20 percent between 1995 and 2002.

According to the MedLine lens, health policy articles followed a very different trajectory. ${ }^{4}$ As the table below shows, policy publications doubled between 1990 and 1995, but a substantial decline can be seen in 2002. Thus, these health policy publications seem to track federal priorities more closely than foundation spending. This may be because a large share of foundation grantmaking is for activities that do not generate journal articles.

In some policy areas, however, foundation grantmaking, policy publications, and the larger policy environment paralleled each other. "Health care reform," a term that came to refer to major change to bring about universal coverage through health insurance, is an example. Health care reform amounted to only 1 percent of the U.S.-focused "policy" publications in 1990 but rose to an astonishing 50 percent in 1995. Grantmaking also increased substantially over those years, from virtually nil to almost 20 percent of the 1995 total. Although health care reform dropped from the Washington policy agenda after the defeat of the Clinton reform proposal, grantmaking related to health reform was higher in 2002 than it had been in 1995. (The issue represented a smaller share of total grantmaking, however.) This may help explain why health care reform still represented a robust 10 percent of the policy publications in $2002 .{ }^{5}$

The problem that most animated health policy discussions was the nation's 40 million uninsured, a policy area that is captured under "health care access" in the Foundation Center's report. Access had accounted for a modest amount of grantmaking in 1995-less than a third of the amount spent on reform, less than half than was spent on "Medicare, Medicaid, HMOs, and private insurance," and less even than was spent on "cost containment/managed care." The 2002 report shows quite a different picture. With health reform out of the policy picture, access had become the leading issue for health care grantmaking related to health policy. Grantmaking for access totaled almost $\$ 70$ million in 2002-a more than 1,000 percent increase over 1995.

Here growth in foundation spending far outpaced increases in MedLine articles on the issue. Policy articles on health care access in the United States, which had increased by more than 50 percent between 1990 and 1995, actually declined by 31 percent between 1995 and 2002. A search that did not include the term "policy" showed a small increase (from 1,230 to 1,321) between 1995 and 2002, but even so, it is clear that publications on access in no way reflected the increase in foundation spending. This again suggests that most health policy spending by foundations was for activities that did not generate journal articles.

The Foundation Center reported substantial increases in funding between 1995 and 2002 for five special topics that had been covered in its earlier report, with very substantial increases for "reproductive health" and "mental health/substance abuse," and with smaller increases for "smoking prevention/tobacco addiction," "end-of-life care/ right-to-die issues," and "HIV/AIDS" policy. Policy publications on all of these issues were relatively uncommon (mental health/substance abuse was the most common, accounting for 7.5 percent of all U.S. policy publications in 2002). With the exception of publications related to tobacco and smoking policy (which increased by 60 percent to 91), the number of journal articles on all of these policy issues decreased between 1995 and 2002.

Reproductive health and abortion is a particularly striking example of an issue that has an ongoing high level of activity in the policy arena but in which the policy research and the policy grantmaking communities have moved in different directions. While grantmaking for reproductive health went from less than \$1 million in 1990 and 1995 to more than $\$ 22$ million in 2002, policy publications on "reproductive health or abortion" decreased from 82 to 57 to 19 . Once again foundation spending did not translate into the activities of policy researchers.

If increases in foundation spending are not necessarily mirrored in increases in publications on the same issues, what happens when foundation spending on an issue decreases? Two issues showed an absolute decline in grantmaking dollars-health care financing and cost containment/managed care, which decreased by 48 percent and 69 percent respectively between 1995 and 2002. Notably, policy publications on those same two issues declined quite similarly, 52 percent and 65 percent, respectively. 
The publication data can hide interesting trends. An example can be found in the policy area of end-of-life care/right-to-die issues, which showed about the same number of policy articles in journals in 1990 and 2002 (230 and 244). The two terms have different meanings. "Right to die" issues deal with contested territory over patients' rights. "End of life care" is a term that often refers to alternatives to aggressive treatment for people who are nearing death. Searches that combine these terms mask a remarkable change that took place between 1990 and 2002, a change that may be partly due to the grantmaking activities of several foundations and that becomes apparent when the terms are searched separately. In 1990 a search on "right to die" produced 201 articles compared to 32 for "end of life." In 2002, "right to die" produced 38 articles compared to 211 for "end of life." Among policy researchers, the concern about the rights of the terminally ill had largely been replaced by concern about appropriate modes of care.

\section{The Importance of Foundations to Health Policy Research}

I have considered foundation giving for health policy from the perspective of both the recent history of federal support for policy-related work and the production of research on health policy as indexed in MedLine. This examination suggests that foundations have been playing an important role in keeping health policy on the public agenda and in calling continued attention to some issues that were falling out of favor.

My analysis also suggests that foundations' grantmaking activity in health policy work does not translate directly into the literature generated by the researchers who produce evidence germane to important policy issues. Yet, the conduct and dissemination of this type of research is an important part of the policy process, especially in an environment where certain politically sensitive issues tend to be systematically under funded by government. For foundations that have a commitment to policy sensitive issues in health care, the place of policy-oriented research in their portfolios merits careful ongoing consideration.

It is also notable that foundations have been providing more support for research training related to policy. In 2002, overall foundation support for health policy research and training totaled almost $\$ 45$ million (exceeding by 50 percent the total of all health policy grantmaking in 1990). A substantial share of this giving funded academic training. The support of research and training has important implications. It bespeaks a long-term commitment to change. It suggests that the demand for health policy research dollars will increase, because the number of health policy scholars is increasing. It also suggests that it will be increasingly difficult to sweep the nation's health policy problems under the rug and, perhaps, that new and more ingenious solutions will be found to our seemingly intractable health care problems.

\section{ENDNOTES}

1. Steven Lawrence, Update on Foundation Health Policy Grantmaking, New York: Foundation Center, 2004.

2. Loren Renz and Steven Lawrence, Health Policy Grantmaking: A Report on Foundation Trends. New York: The Foundation Center, 1998. See also, Loren Renz and Steven Lawrence, "Health Policy Grantmaking by Foundations in the 1990s." Health Affairs 17 (September/October 1998) 216-229.

3. For a full account of AHCPR's history and near demise, see Bradford H. Gray, Michael K. Gusmano, and Sara R. Collins, AHCPR and the Changing Politics of Health Services Research. Health Affairs. 2003 Jan.-June; Suppl: W3-283-307.

4. I limited my search to articles pertaining to the United States, since the Update on Foundation Health Policy Grantmaking found that less than 6 percent of the health policy grant dollars in 2002 were for international activities.

5. The number of publications on the topic almost doubled (from 216 to 419) between 2002 and 2003. No other topic showed such a large change in these two years.

Download Health Policy Research and Foundation Grantmaking at www.fdncenter.org/research/.

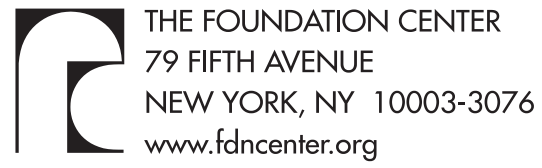

Advancing Knowledge about Philanthropy 